\title{
CORRESPONDENCE
}

\section{Clinical Environmental Medicine}

by Prof. Dr. med. Caroline Herr, Prof. Dr. med. Isabelle Otterbach, Prof. Dr. med. Dennis Nowak, Prof. Dr. med. Claudia Hornberg, Prof. Dr. med. Thomas Eikmann, Prof. Dr. med. Gerhard-Andreas Wiesmüller in volume $30 / 2008$

\section{In Reply:}

The authors thank Dr von Baehr for his comments on the use of the lymphocyte transformation test in the practice of environmental medicine.

According to the notes of the committee for methods and quality assurance in environmental medicine at the Robert Koch-Institute (1), the use of the LTT currently has to be rated as follows:

- The unspecific LTT is suitable only for confirming severe immunological defects. Slightly impaired lymphocyte functions, which may be due to harmful environmental substances, cannot be captured owing to the lacking specificity of the "unspecific" LTT and the notable physiological range.

- The "specific" LTT indicates only prior contact to a specific allergen, but not its effect within in the organism.

- A positive finding in the "specific" LTT is no confirmation of the clinical manifestation of an allergy; a negative finding, however, does not exclude an allergic reaction. A positive finding for the "specific" LTT therefore should be evaluated only in association with clinical data.

The "specific" LTT has a confirmed position in the diagnosis of allergies to medical drugs.

- The meaningfulness of the "specific" LTT for environmental disorders is limited and has to be confirmed by studies. Since no published validations for the "specific" LTT currently exist, its clinical use cannot be advocated. DOl: 10.3238/arztebl.2008.0864b

\section{REFERENCES}

1. Kommission „Methoden und Qualitätssicherung in der Umweltmedizin“ am Robert-Koch-Institut. Diagnostische Relevanz des Lymphozytentransformationstestes in der Umweltmedizin. Bundesgesundheitsbl Gesundheitsforsch - Gesundheitsschutz 2002; 45: 745-49.

Prof. Dr. med. Caroline Herr

Universitätsklinikum Gießen und Marburg GmbH

Standort Gießen

Friedrichstr. 16

35392 Gießen, Germany

Fax: 0641/99-41459

Sybille.Angrick@hygiene.med.uni-giessen.de

\section{Conflict of interest statement}

The authors of both the letter and the reply declare that no conflict of interest exists according to the guidelines of the International Committee of Medical Journal Editors. with the same idea: that their complaint is comprehensively considered and dealt with.

\section{REFERENCES}

1. Merk KH: Allergische Berufsdermatosen, Stellungnahme zur In-vitroDiagnostik. Hautarzt 2004; 55: 31-4.

2. Pichler WJ, Tilch J: The lymphocyte transformation test in the diagnosis of drug hypersensitivity. Allergy 2004; 59: 809-20. 